\title{
Resiliencia del mercado turístico urbano ante la crisis de la COVID-19. El caso de Málaga
}

\section{Resilience of the urban tourist market in the face of the COVID-19 crisis. The case of Malaga}

\author{
Beatriz Benítez-Aurioles \\ bbaurioles@uma.es@0000-0002-4224-9184 \\ Facultad de Ciencias Económicas y Empresariales. Universidad de Málaga. \\ Calle El Ejido, 6. 29013 Málaga, España
}

\section{INFO ARTÍCULO}

Recibido: $14 / 11 / 2021$

Revisado: $16 / 12 / 2021$

Aceptado: 24/12/2021

\section{PALABRAS CLAVE}

Resiliencia

Turismo urbano

COVID-19

Hoteles

Airbnb

Impactos

\section{KEYWORDS}

Resilience

Urban tourism

COVID-19

Hotels

Airbnb

Impacts

\begin{abstract}
RESUMEN
Este artículo tiene como objetivo verificar la resiliencia del turismo urbano ante la crisis de la COVID-19 e identificar sus rasgos principales, tomando como referencia la ciudad de Málaga. Se utilizará el enfoque metodológico que proporciona el análisis económico para analizar la dinámica que se ha registrado en el mercado de alojamientos, tanto convencionales (hoteles) como el de viviendas turísticas de alquiler a corto plazo. Los datos se refieren a indicadores de demanda, de oferta y de precios para el periodo comprendido entre septiembre de 2018 y el mismo mes del año 2021. Los resultados del análisis evidencian claros signos de recuperación del mercado turístico a partir de la primavera de 2021. Más concretamente, se constata el protagonismo que adquieren los residentes en España en la demanda de alojamiento hotelero. Asimismo, en el mercado peer-to-peer se confirma que, meses después del levantamiento de las restricciones a la movilidad, se superaron los niveles de actividad alcanzados antes de la pandemia. Sobre esa base, parece pertinente reabrir y replantear el debate sobre la capacidad de carga de las ciudades y la conveniencia de regular el mercado de alojamientos turísticos.
\end{abstract}

\begin{abstract}
This article aims to verify the resilience of urban tourism in the face of the COVID-19 crisis, and identify its main features, taking the city of Malaga as a reference. The methodological approach provided by the economic analysis will be used to analyze the dynamics that have been registered in the accommodation market, both conventional (hotels) and short-term rental tourist housing. The data refer to demand, supply and price indicators for the period between September 2018 and the same month in 2021. The results of the analysis show clear signs of recovery in the tourism market as of spring 2021. More specifically, the role that residents of Spain acquire in the demand for hotel accommodation is confirmed. Likewise, in the peer-to-peer market, it is confirmed that, months after the lifting of mobility restrictions, the activity levels reached before the pandemic were exceeded. On this basis, it seems pertinent to reopen and rethink the debate on the carrying capacity of cities and the advisability of regulating the tourist accommodation market.
\end{abstract}




\section{INTRODUCCIÓN}

Las crisis turísticas han sido, relativamente, frecuentes. A veces han afectado a destinos concretos cuando, por ejemplo, se han producido ataques terroristas (Corbet et al., 2019), desastres naturales (Rosselló et al., 2020), o cuando ha crecido la incertidumbre política o económica (Benítez-Aurioles, 2019a; Benítez-Aurioles, 2021a). Asimismo, en las dos últimas décadas se han registrado crisis globales como consecuencia de los ataques terroristas del 11 de setiembre de 2001 (Blake \& Sinclair, 2003), de la propagación del virus del síndrome respiratorio agudo grave (SARS) en 2003 (McKercher \& Chon, 2004), o de la Gran Recesión de 2007 (Pechlaner \& Frehse, 2010). Ahora bien, ninguna de ellas es comparable con la crisis turística que ha provocado la COVID-19 que ha sido responsable del peor año en la historia del turismo (UNWTO, 2021). En efecto, para tratar de contener la expansión del virus, a principios de 2020, se generalizaron las restricciones a los movimientos de personas, las cuarentenas, los encierros y la prohibición de los viajes. En esas condiciones, el colapso de la industria turística fue inevitable.

En el caso concreto de España, tras la declaración del estado de alarma, en marzo de 2020 se suspendió la apertura al público de los establecimientos de alojamiento turístico. En mayo se flexibilizaron algunas medidas, aunque, debido a las restricciones a la movilidad, la actividad hotelera siguió siendo mínima durante los meses de verano. Además, ante la aparición de nuevos rebrotes y medidas restrictivas, dicha actividad fue muy escasa también en los últimos meses del año (Exceltur, 2021). El resultado fue que 2020 fue un año nefasto para el turismo en España. En 2021, en cambio, el progresivo avance de la vacunación y el levantamiento de las restricciones que se habían decretado permitieron, en cierta medida, la recuperación de la actividad turística que empezó a demostrar la resiliencia que había tenido en el pasado (Benítez-Aurioles, 2020a).

En este contexto, el objetivo de este artículo es analizar la capacidad de recuperación del turismo urbano ante la crisis de la COVID-19, tomando como referencia la ciudad de Málaga. Consideraremos el turismo urbano en el mismo sentido que lo hace la Organización Mundial del Turismo: “Un tipo de actividad turística que tiene lugar en un espacio urbano con sus atributos inherentes caracterizados por una economía no agrícola basada en la administración, las manufacturas, el comercio y los servicios y por constituir nodos de transporte". Y añade: "Los destinos urbanos ofrecen un espectro amplio y heterogéneo de experiencias y productos culturales, arquitectónicos, tecnológicos, sociales y naturales para el tiempo libre y los negocios" (UNWTO, 2019).

A partir de aquí este trabajo se organiza en los siguientes apartados. En primer lugar, presentaremos el marco teórico en el que se sitúa. A continuación, expondremos la metodología. Más adelante, se dedicará un epígrafe a la presentación y la discusión de los resultados. Terminaremos con las conclusiones.

\section{MARCO TEÓRICO}

A principios de la década de los noventa, Ashworth (1992) planteó la siguiente pregunta: ¿Hay un turismo urbano? Su respuesta se articulaba en torno a tres afirmaciones que, por entonces, necesitaban demostración empírica. La primera era que el turismo urbano existe y que puede ser estudiado de forma autónoma. La segunda se refería a que el turismo urbano no había recibido suficiente atención por parte de los investigadores. Y la tercera sostenía que el turismo urbano era lo suficientemente importante como para justificar su estudio. Pues bien, trascurridas tres décadas, se ha acumulado suficiente evidencia que demuestra no sólo que el turismo urbano existe, sino que tiene la importancia suficiente para merecer un tratamiento específico tanto a nivel académico como político, social y económico.

La configuración de un marco teórico coherente y maduro para el análisis del turismo urbano empezó a gestarse a medida que las ciudades comenzaron a dejar de ser simples gateways para consolidarse como destinos, tanto para los que viajaban por motivos de negocio como para aquellos que lo hacían por placer (Zheng et al., 2020). Es cierto que, tal como señaló Ashworth (2003), durante algún tiempo los que estudiaban el turismo desatendieron las ciudades y los que estudiaban las ciudades desatendieron el turismo. De hecho, antes de la década de los ochenta del siglo pasado, la investigación sobre turismo urbano estaba 
fragmentada y no se reconocía como un campo de investigación independiente (Edwards et al., 2008). No obstante, en los últimos años el panorama ha cambiado de forma sustancial y la literatura específica sobre el turismo urbano ha experimentado un enorme crecimiento. Así, por ejemplo, una búsqueda del topic "urban tourism" en la base de datos Web of Science (WOS) concentra casi el $80 \%$ de todos los documentos encontrados en los últimos diez años. Incluso, desde 2015 se publica una revista por la editorial Emerald dedicada específicamente a la investigación sobre el turismo urbano: International Journal of Tourism Cities.

El interés académico por el turismo urbano fue creciendo a medida que también lo hacía el fenómeno objeto de estudio. En este sentido, la importancia que alcanzó el turismo en determinadas ciudades aumentó la presión de los turistas sobre ciertos entornos urbanos lo que provocó la aparición de protestas de la población local (Smith et al., 2019), el inicio de la difusión de términos como overtourism o turismofobia (Namberger et al., 2019; UNWTO, 2018), y el rechazo de los residentes hacia el mercado peer-to-peer (p2p) de alojamientos turísticos (Ikeji \& Nagai, 2020). Precisamente, el desarrollo de este mercado, gracias a plataformas como Airbnb, es fundamental para entender la dimensión que ha alcanzado el turismo urbano y el debate social que ha generado (Oskam, 2020), donde se han puesto de manifiesto ciertos conflictos entre los actores implicados (Comendador-Sánchez et al., 2021).

Entre la abundante literatura que se ha generado en torno al mercado p2p de alojamientos turísticos (Dann et al., 2019; Dolnicar, 2019; Guttentag, 2019; Hati et al., 2021; Ozdemir \& Turker, 2019; Prayag \& Ozanne, 2018; Sainaghi, 2020) tiene un especial interés la relacionada con los distintos impactos que se han documentado. Por un lado, nos encontramos con investigaciones que han confirmado sus interacciones con otros mercados como el de alojamientos convencionales (hoteles) (Benítez-Aurioles, 2019b) o el de alquiler y compraventa de viviendas (Benítez-Aurioles \& Tussyadiah, 2020). Por otro, se han analizado, desde distintas perspectivas, los efectos externos negativos en zonas residenciales en forma de ruidos, atascos y escasez de aparcamiento, así como los problemas que supone la gestión de residuos, entre otras cuestiones (Gurran \& Phibbs, 2017). En torno a estos temas siguen abiertas algunas discusiones en el ámbito académico. No obstante, el debate sobre la pertenencia del mercado p2p, en general, y de Airbnb, en particular, como la plataforma que lidera el alquiler de viviendas a corto plazo en el mundo, a la denominada sharing economy o economía compartida o colaborativa parece resuelto. En efecto, en un principio se había argumentado que Airbnb es "prácticamente sinónimo de economía colaborativa" (Schor, 2016). Sin embargo, algunos consideraron relevante aclarar si Airbnb es parte de la economía colaborativa (Reinhold \& Dolnicar, 2018). Lógicamente, cualquier consideración sobre este tema dependerá de lo que se entienda por economía colaborativa. En este contexto, si aceptamos que Airbnb es una organización con fines de lucro que cobra una comisión sobre los precios de alquiler cuando los propietarios reciben huéspedes, entonces pertenecería a lo que Belk (2014) denomina pseudo-sharing economy. Es obvio que, a pesar de los esfuerzos de Airbnb por presentarse como representante de la economía colaborativa y promotora de experiencias solidarias (Benítez-Aurioles, 2018a), la realidad es que las transacciones se realizan en el mercado e implican un flujo de dinero que compensa la prestación de un servicio. De esta forma, Airbnb habría de considerarse como una plataforma que busca el beneficio comercial (Oskam \& Boswijk, 2016; Hajibaba \& Dolnicar, 2018).

En cuanto a los usuarios de las plataformas (anfitriones y huéspedes) existe una amplia gama de contribuciones, muchas de las cuales se basan en encuestas, que demuestran que, por un lado, la demanda de alojamiento en el mercado p2p se explica, entre otros factores, por razones económicas (Camilleri \& Neuhofer, 2017; Guttentag, 2015; Möhlmann, 2015; Priporas et al., 2017; Tussyadiah, 2016; Tussyadiah \& Pesonen, 2016; Tussyadiah \& Zach 2017; Wiles \& Crawford, 2017; Wu et al., 2017) y, por otro, desde el punto de vista de la oferta, también se ha dejado clara la importancia de las motivaciones económicas (Deale \& Crawford, 2018; Ikkala \& Lampinen, 2014; Karlsson \& Dolnicar, 2016).

Sobre la base anterior, el marco teórico pertinente para el análisis del mercado turístico urbano, con independencia del peso que pudieran tener los intercambios en el mercado p2p, sería el análisis económico en donde los agentes reaccionan a los incentivos maximizando sus funciones de utilidad o de beneficio. Este enfoque no es óbice para que una comprensión global del turismo urbano exija una perspectiva más amplia y, en particular, el concurso de otras ciencias sociales (Ashworth \& Page, 2011; Hocevar \& Bartol, 2021). Ahora bien, el marco teórico que aplicamos se justifica por la idea de que para entender los cambios que 
ha provocado la crisis de la COVID-19 en el mercado turístico urbano son adecuados los argumentos que proporciona el análisis económico.

Se plantea, por tanto, la conveniencia de apoyar el estudio del turismo urbano en el análisis de la oferta, de la demanda y de los precios como vectores básicos que determinan el funcionamiento de cualquier mercado. Esta aproximación tiene más interés en la medida en que el propio turismo urbano esté demostrando resiliencia ante la crisis de la COVID-19 y el mercado, en consecuencia, muestre síntomas de recuperación. A partir de ahí, adquirirían un nuevo impulso los debates previos a la pandemia sobre la capacidad de carga turística de algunas ciudades. En este contexto, resulta pertinente determinar, en primer término, si el turismo urbano se está recuperando y, si es así, en qué medida se están reproduciendo las características que tenía antes de la pandemia. Este artículo pretende avanzar en esa línea.

\section{METODOLOGÍA}

De acuerdo con lo expuesto en el apartado anterior, el análisis que proponemos exige información sobre las variables básicas que definen el funcionamiento de los mercados: oferta, demanda y precios. Para el mercado de alojamientos turísticos convencionales el Instituto Nacional de Estadística (INE) facilita una serie de datos relativamente completos (González \& Velasco, 2021). En particular, la Encuesta de Ocupación Hotelera proporciona, por el lado de la demanda, información sobre el número de viajeros, pernoctaciones y estancia media, y, por el lado de la oferta, se pueden consultar, entre otras variables, el número estimado de establecimientos abiertos, plazas, y grados de ocupación. Asimismo, se suministra información sobre el empleo en el sector (INE, 2019). El hecho de que los datos tengan una desagregación mensual y por puntos turísticos, es decir, por municipios en los que la concentración de la oferta turística es muy significativa, hacen que sean, particularmente, apropiados para el análisis que pretendemos. Adicionalmente, para el tratamiento de algunas variables relacionadas con la rentabilidad del sector hotelero se ha utilizado el barómetro que publica Exceltur (2021).

Por el contrario, el conocimiento del mercado p2p de alojamientos turísticos sigue tropezando con la escasez de estadísticas oficiales, aunque el INE (2021a) proporciona de forma experimental una estimación de la ocupación en alojamientos turísticos a partir de datos de plataformas digitales. No obstante, en el momento de redactar este trabajo el último dato disponible se refiere a diciembre de $2019 \mathrm{y}$, por tanto, sobre esa base no es posible analizar los efectos que ha causado la COVID-19. En estas circunstancias, la alternativa se encuentra en la recogida de información, a través de técnicas de scraping, de los anuncios publicados por plataformas que facilitan la comercialización del alquiler de viviendas a corto plazo, como Airbnb.

La elección de Airbnb para aproximarnos al conocimiento del mercado p2p de alojamientos turísticos se basa en la indiscutible posición de liderazgo que ha alcanzado entre las plataformas dedicadas a la comercialización de viviendas particulares a corto plazo (Hajibaba \& Dolnicar, 2018). En 2017 ya tenía más capacidad de alojamiento que el conjunto de las cinco principales cadenas hoteleras del mundo (Hartmans, 2017). Y en 2021 alcanzó más de 7 millones de anuncios de alojamientos repartidos por unas 100.000 ciudades de, prácticamente, todos los países del mundo (Deane, 2021). Las previsiones apuntan a que esas cifras seguirán aumentando en los próximos años (Gassmann et al., 2021).

Pues bien, existen iniciativas privadas, como AirDNA (2021) o InsideAirbnb (2021), que recopilan los datos que caracterizan a la oferta de Airbnb y los ponen a disposición de los interesados. En particular, la base de datos que proporciona InsideAirbnb (2021) ha sido frecuentemente utilizada para la investigación académica (Dann et al., 2019) ya que contiene una información muy completa para un amplio conjunto de ciudades del mundo. No obstante, al margen de ciertas críticas puntuales (Alsudais, 2021), posee algunas limitaciones destacables. Así, los datos no suelen estar disponibles a intervalos regulares sino en determinadas fechas lo que, a veces, dificulta hacer comparaciones sobre la evolución temporal de mercados concretos. Además, se trata básicamente de datos que caracterizan a la oferta de los alojamientos. En este punto conviene precisar que existe evidencia de que la demanda en el mercado $p 2 p$ se suele concentrar en una parte de la oferta y que un elevado porcentaje de alojamientos anunciados no reciben solicitudes de reserva y, por tanto, no son 
ocupados (Benítez-Aurioles, 2020b). Los precios, en consecuencia, no son precios a los que se realizan los intercambios, sino que son, más bien, el reflejo de la disposición a ofrecer de los anfitriones.

Por otro lado, la base de datos de InsideAirbnb no permite conocer de forma directa el grado de ocupación de los alojamientos por lo que la información relativa a la demanda solo puede deducirse por métodos indirectos. Por ejemplo, de acuerdo con Airbnb (2021a) solo los huéspedes que han completado una estancia pueden dejar su evaluación. Por tanto, es posible utilizar el número de evaluaciones como proxy de la ocupación efectiva de cada alojamiento (Hu \& Lee, 2020). Es necesario señalar que, según las normas establecidas por Airbnb (2021a), los huéspedes disponen de 14 días desde la fecha de salida para enviar su evaluación, con lo que es posible que se produzca un cierto desfase entre el número de evaluaciones y el mes en el que, efectivamente, se ha ocupado el alojamiento que, en cualquier caso, no afecta a su capacidad como indicador de la evolución de la demanda.

Para el análisis de los precios hemos seleccionado los anuncios que tenían al menos 5 evaluaciones. De esta manera, intentamos asegurar que se trata de alojamientos que no sólo han sido comercializados en el mercado, sino que no lo han sido de forma esporádica. Sobre esa base, y de acuerdo con los resultados de investigaciones previas (Benítez-Aurioles, 2018b; Wang \& Nicolau, 2017) se han seleccionado las variables que contiene la tabla 1.

Tabla 1. Descripción de las variables.

\begin{tabular}{|l|l|}
\hline \multicolumn{1}{|c|}{ Variable } & \multicolumn{1}{c|}{ Descripción } \\
\hline In P & Logaritmo natural del precio \\
\hline AC & Número máximo de huéspedes \\
\hline EH & 1 si se trata de una vivienda completa (0 si no) \\
\hline DI & Distancia en kilómetros al centro de la ciudad \\
\hline SH & 1 si el anfitrión posee la etiqueta Superhost (0 si no) \\
\hline In L & Logaritmo natural del número de anuncios por anfitrión \\
\hline IB & 1 si la opción reserva instantánea está activada $(0$ si no) \\
\hline NR & Número de evaluaciones que posee el anuncio \\
\hline
\end{tabular}

A partir de esas variables realizaremos la siguiente estimación donde el subíndice se refiere a cada alojamiento y e el término de error:

$$
\ln P_{i}=\beta_{1} A C_{i}+\beta_{2} E H_{i}+\beta_{3} D I_{i}+\beta_{4} S H_{i}+\beta_{5} \ln L_{i}+\beta_{6} I B_{i}+\beta_{7} N R_{i}+\beta_{0}+e_{i}
$$

Lo previsible es que los alojamientos tengan un precio más elevado a medida que crece el número de huéspedes potenciales. Asimismo, cabe esperar que los alojamientos que consisten en una vivienda completa tengan un precio superior respecto a los que ofrecen una habitación privada o compartida.

Por otro lado, Airbnb otorga el distintivo de Superhost a aquellos anfitriones que, en promedio, han obtenido una calificación general de no menos de 4,8 estrellas (sobre 5), responden, al menos, al 90\% de los mensajes en un plazo máximo de 24 horas, consiguen, al menos, 10 visitas por año, y solo cancelan reservas en circunstancias excepcionales (Airbnb, 2021b). Cabría suponer que los esfuerzos invertidos por los anfitriones para obtener (y mantener) la etiqueta Superhost son compensados por los mayores ingresos derivados de la mayor disposición a pagar de los huéspedes (Liang et al., 2017). Por tanto, debería existir una relación directa entre el precio del alojamiento y el distintivo Superhost.

Por último, se ha demostrado que los anfitriones profesionales (aquellos que ofrecen más de un alojamiento) son capaces de adaptar sus precios de manera más eficiente ante las fluctuaciones de la demanda 
y que suelen cobrar precios mayores por sus alojamientos (Li et al., 2019). Por tanto, también cabría esperar que a medida que crece el número de anuncios por anfitrión también aumentará el precio.

Análogamente, existe evidencia de que, en términos generales, cuanto mayor sea la distancia que separa el alojamiento del centro de la ciudad sus precios decrecen (Benítez-Aurioles, 2018c). Por último, se ha confirmado de forma reiterada que el número de evaluaciones se correlaciona negativamente con el precio de los alojamientos (Gibbs et al., 2018; Magno et al., 2018) lo que, en principio, podría ser una consecuencia lógica de la ley de la demanda: ceteris paribus, a medida que disminuye el precio crece la demanda.

El ámbito de estudio es la ciudad de Málaga. La elección se basa, de entrada, en la importancia que, en términos absolutos, tiene su actividad turística entre las ciudades españolas. De acuerdo con el informe elaborado por Exceltur (2017), con datos referidos a 2016, la ciudad de Málaga ocupaba el quinto lugar, tras Barcelona, Madrid, Sevilla y Valencia, entre las 22 ciudades españolas analizadas, según el número de plazas de alojamientos turísticos (hoteles más viviendas p2p); y se situó en el cuarto lugar, tras Barcelona, Madrid y Valencia, entre las ciudades de más de 500 mil habitantes según el ranking de competitividad turística. Para 2019 se estimó que el impacto económico total del turismo en la ciudad de Málaga estaría cercano a los 3 mil millones de euros (Observatorio turístico de la ciudad de Málaga, s.f.). Si tenemos en cuenta que, según el INE (2021b) la renta total de la ciudad ascendía, en 2018, a algo más de 6 mil millones de euros, el impacto económico del turismo en la ciudad podría estar cercano al $50 \%$. En términos de empleo, en cambio, las 34.500 personas dedicadas a la actividad turística supondrían algo más del $12 \%$ de los trabajadores afiliados a la seguridad social en la ciudad (Ayuntamiento de Málaga, 2021). En cualquier caso, con independencia de las discrepancias que puedan surgir respecto a las estimaciones realizadas, parece evidente que el turismo en la ciudad de Málaga tiene un peso destacable que la sitúan entre los destinos turísticos urbanos más importantes de España.

Otro elemento que hace que el análisis del turismo urbano en Málaga posea un especial interés se refiere al peso que tiene, en esta ciudad, el mercado p2p de alojamientos turísticos. Algunas estimaciones la situaban, con datos de 2017, como la ciudad española donde la penetración de Airbnb (camas ofrecidas por Airbnb respecto a camas hoteleras) era más elevada (Jiménez et al. 2021). Por consiguiente, dado el papel que ha desempeñado dicho mercado en la consolidación del turismo urbano, la ciudad de Málaga constituye un caso representativo y oportuno para el análisis de la resiliencia del turismo urbano ante la crisis de la COVID-19.

En cuanto al ámbito temporal hemos tomado como referencia el periodo comprendido entre septiembre de 2018 y el mismo mes del año 2021, es decir, antes de la pandemia y una vez que el sector turístico ha dado muestras de recuperación. No obstante, es necesario advertir que, dada la excepcionalidad que se vivió durante algunos meses de la pandemia, no siempre dispusimos de datos para todos los meses del periodo señalado, lo que ha provocado cierta discontinuidad en las series analizadas.

\section{RESULTADOS Y DISCUSIÓN}

La información disponible y las peculiaridades de cada mercado hacen aconsejable diferenciar el análisis de los resultados obtenidos para los hoteles y para los de Airbnb.

\subsection{Hoteles}

La figura 1 recoge la evolución mensual de algunos indicadores de demanda del sector hotelero en la ciudad de Málaga. No se dispone de datos entre abril y junio de 2020 debido a la situación que supuso la declaración del estado de alarma el 14 de marzo que se prolongó hasta el 21 de junio. En cualquier caso, se aprecia un comportamiento claramente diferenciado antes y después de la vigencia del estado de alarma. Entre septiembre de 2018 y marzo de 2020, tanto los viajeros como las pernoctaciones de los residentes en el extranjero superaron ampliamente a las de los nacionales. De hecho, en septiembre de 2018 y de 2019 los residentes en 
el extranjero supusieron más del doble, tanto en términos de viajeros como de pernoctaciones registradas en los hoteles, que los nacionales. En septiembre de 2020, en cambio, eran los residentes en España los que duplicaban, en ambas variables, a los extranjeros. Al final del periodo las series se aproximan, aunque seguían siendo mayoría los viajeros y las pernoctaciones de los españoles. El comportamiento observado al final del periodo considerado es similar al registrado en el último trimestre de 2019: fuerte caída en el número de viajeros y pernoctaciones de los extranjeros, por motivos estacionales, e incremento en el de los españoles.

En definitiva, cuando en julio de 2020 se recupera la información estadística los turistas residentes en España superan a los residentes en el extranjero. Es decir, es la demanda turística nacional la que protagoniza la recuperación que experimenta el sector y que resulta aún más evidente desde mayo de 2021. Es cierto que, desde entonces, también se aprecia un aumento tanto en el número de viajeros como de pernoctaciones de los extranjeros, aunque sin alcanzar los niveles previos a la pandemia. En cambio, el número de viajeros y de pernoctaciones de los nacionales experimentan crecimientos importantes superando, incluso, las cifras de los años precedentes. Así, el número de viajeros y de pernoctaciones en agosto de 2021 de los residentes en España supusieron las más altas de la historia. Y si comparamos los datos de viajeros y pernoctaciones de septiembre de 2021 con los del mismo mes de 2019, los de los extranjeros disminuyeron en un $48 \%$ y en un $39 \%$, respectivamente, mientras que los de los nacionales aumentaron en un $15 \%$ y en un $45 \%$ respectivamente.

Esta evidencia refuerza la idea de que la pandemia ha favorecido la sustitución de los viajes internacionales por los nacionales lo cual está en línea con otros estudios previos. Por ejemplo, Cooper (2003) observó que, ante la epidemia del SARS de 2003, los turistas japonenses evitaron ciertos destinos, pero no dejaron de viajar y, en consecuencia, optaron por los viajes interiores. Más recientemente, para el caso de España, Benítez-Aurioles (2021b) demostró que, como consecuencia de la pandemia de la COVID-19, había disminuido el número de viajes al extranjero mientras que creció el de los realizados dentro de España y, más concretamente, los que tenían como destino la propia Comunidad Autónoma de residencia del turista. Todo lo cual acredita la capacidad del turismo nacional para compensar la caída del turismo internacional al menos en España (Arbulú et al., 2021).

Otro dato relevante se refiere al aumento de la estancia media total que alcanzó los 2,61 días en agosto de 2021. Esta cifra es la más alta desde, al menos, 2005 y es uno de los elementos que está caracterizando la resiliencia del turismo en los entornos urbanos lo cual proporciona pistas, no sólo para la gestión de los establecimientos hoteleros, sino también para las campañas de promoción puestas en marcha en el ámbito público.

Por otro lado, los indicadores de oferta representados en la figura 2 confirman la recuperación del mercado a partir de mediados de 2021. El número de habitaciones estimadas alcanzó en agosto y septiembre de 2021 sus máximos históricos, lo que sugiere que, no sólo se produjo la reapertura de establecimientos hoteleros que habían cerrado durante la pandemia, sino que también hubo nuevas incorporaciones al mercado. El hecho de que, a pesar de ese crecimiento en el número de habitaciones estimadas, su grado de ocupación también haya crecido se explica, lógicamente, por la recuperación de la demanda turística. El resultado final fue un aumento del empleo que, en pocos meses, casi se triplica al pasar de los 589 en febrero de 2021 a los 1.589 en septiembre de ese mismo año, muy próximo al nivel alcanzado antes de la pandemia. Este es otro dato que confirma la resiliencia del turismo urbano en la ciudad de Málaga ante la crisis de la COVID-19.

Finalmente, la figura 3 recoge la evolución de la tarifa media diaria (ADR, Average Daily Rate) y de los ingresos por habitación disponible (RevPAR, Revenue per Available Room). El ADR representa los ingresos medios diarios por habitación ocupada. La información estadística se recupera en octubre de 2020 y, desde marzo de 2021, se aprecia una subida sostenida del ADR que se hace, particularmente, intensa durante julio y agosto. En septiembre de 2021 vuelve a disminuir, siguiendo la pauta de los años anteriores. El hecho de que el ADR haya experimentado elevaciones importantes los meses en los que, precisamente, aumentó tanto la demanda como la oferta de habitaciones, es una evidencia que justifica, aún más, la resiliencia que ha demostrado el turismo urbano en Málaga tras la pandemia. Además, de acuerdo con el análisis económico más elemental, la subida de los precios de las habitaciones, si se incrementa la oferta, solo puede explicarse por un incremento aún mayor de la demanda que, tal como se ha señalado, recibió un impulso decisivo por parte de los residentes en España. 
Beatriz Benítez-Aurioles / REA N. 43 (2022) 71-88
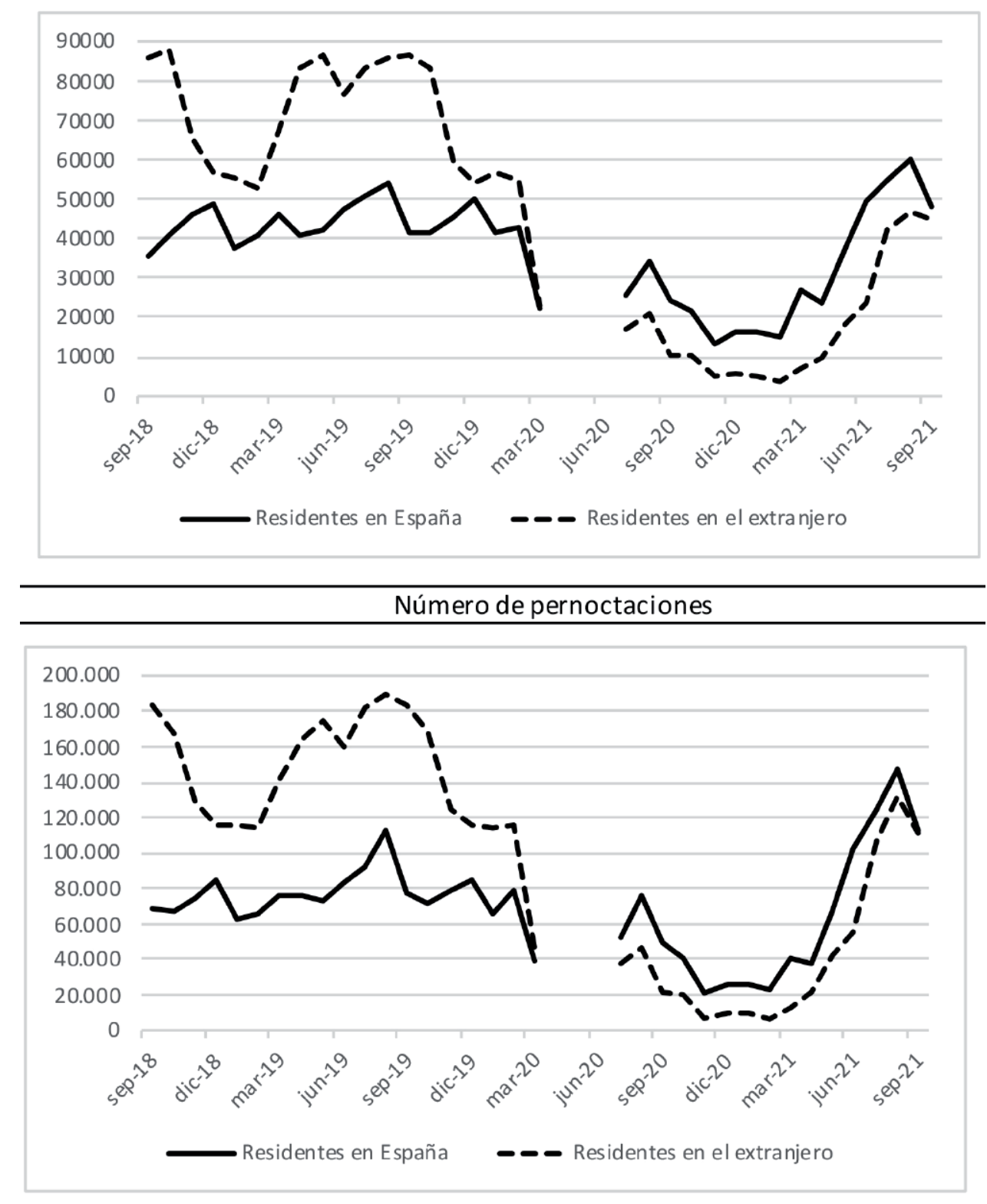

Estancia media (días)

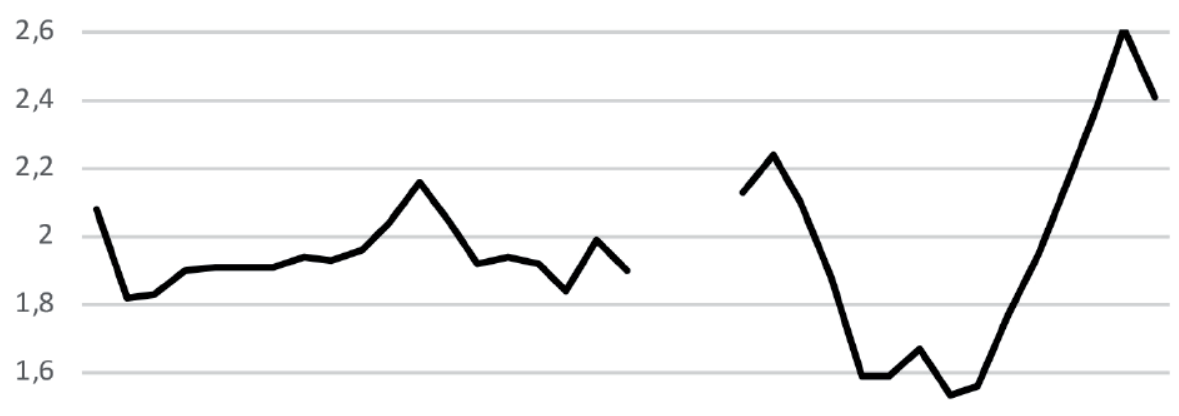

1,4

1,2

1

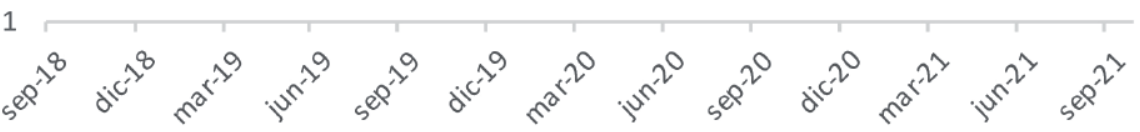

Figura 1. Indicadores de demanda en el sector hotelero en la ciudad de Málaga.

Fuente: Elaboración propia a partir de INE (2021c).

(c) Editorial Universidad de Sevilla 2022 | Sevilla, España| CC BY-NC-ND 4.0 | e-ISSN: 2340-2776 | doi: https://dx.doi.org/10.12795/rea.2022.i43.04 
Beatriz Benítez-Aurioles / REA N. 43 (2022) 71-88
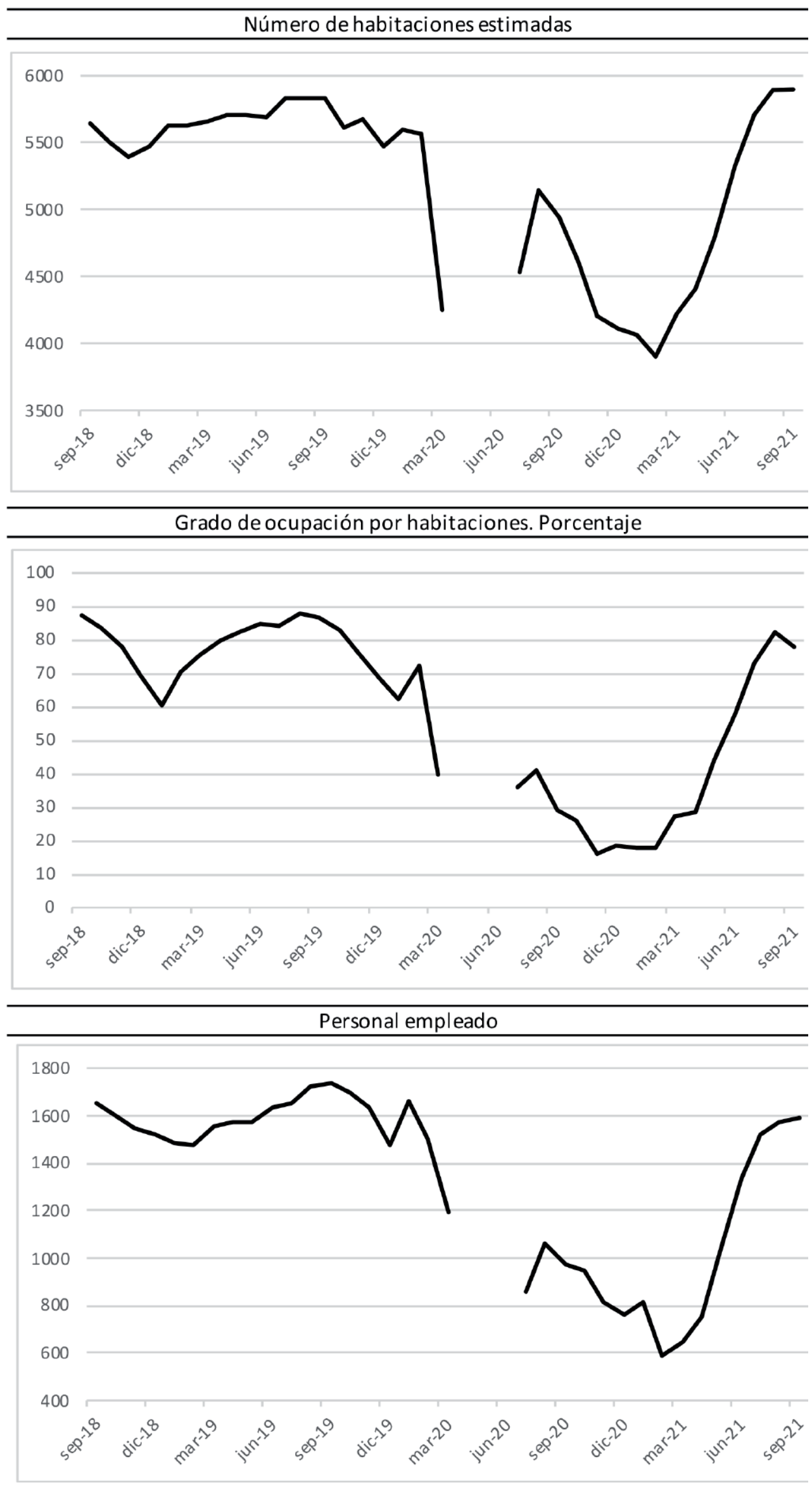

Figura 2. Indicadores de oferta en el sector hotelero en la ciudad de Málaga. Fuente: Elaboración propia a partir de INE (2021c).

(c) Editorial Universidad de Sevilla 2022 | Sevilla, España| CC BY-NC-ND 4.0 | e-ISSN: 2340-2776 | doi: https://dx.doi.org/10.12795/rea.2022.i43.04 
La RevPAR, por su parte, es uno de los indicadores básicos de rentabilidad hotelera y es, simplemente, el producto del ADR y de la ocupación por habitación. Lógicamente, su evolución está condicionada por esas dos variables. Pues bien, desde febrero de 2021 el RevPAR ha tenido crecimientos medios mensuales en torno al $40 \%$, lo cual está en línea con los resultados comentados anteriormente.
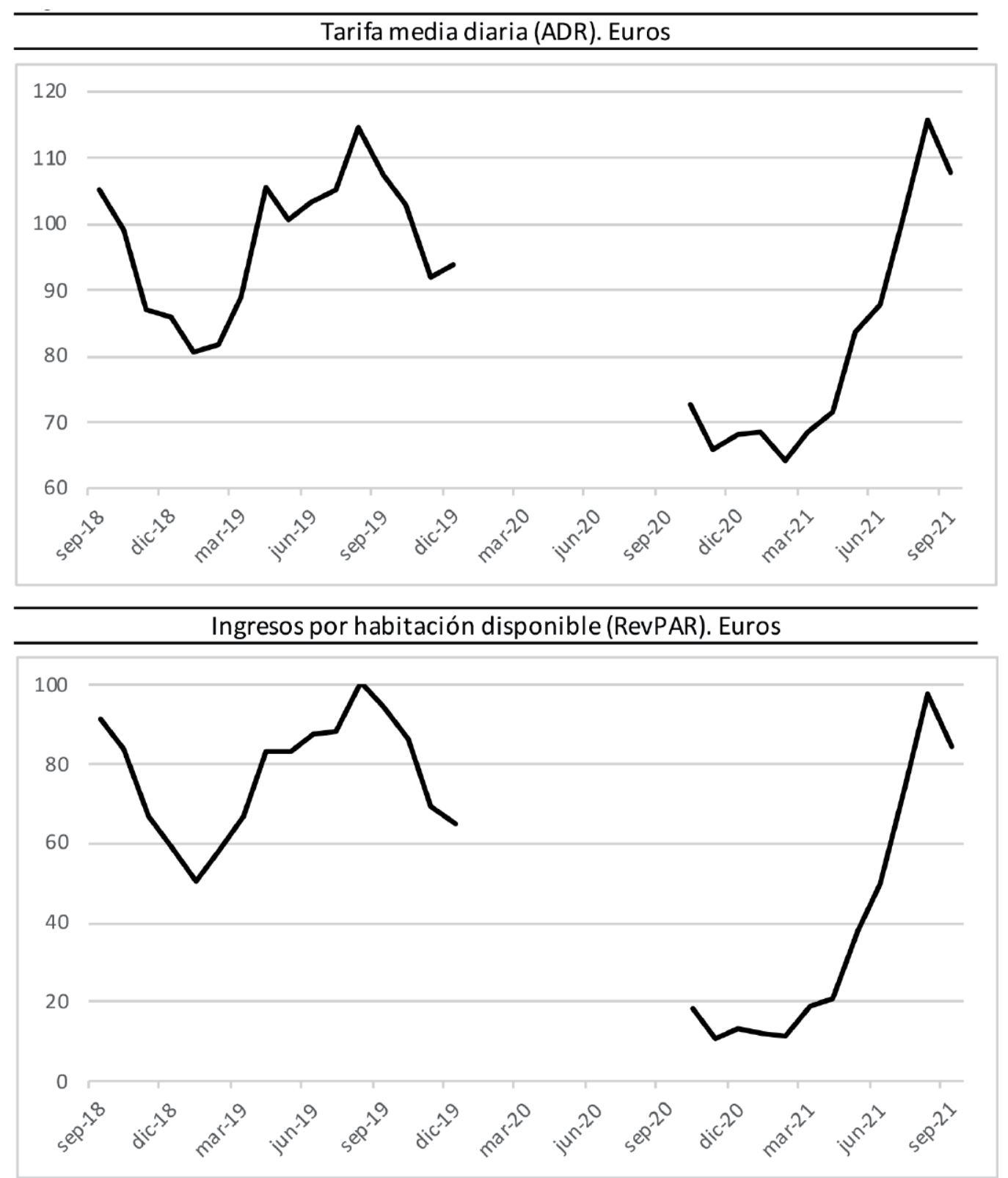

Figura 3. Indicadores de rentabilidad. Fuente: Elaboración propia a partir de INE (2021c).

\subsection{Airbnb}

Respecto al comportamiento del mercado p2p, en general, y de la comercialización de alojamientos a través de Airbnb, en particular, se tomará como indicador de la demanda la evolución en el número de evaluaciones que obtuvieron los anuncios que estaban activos el 30 de septiembre de 2021. En la figura 4 observamos, en consonancia con lo detectado para la demanda hotelera, la práctica ausencia de movimientos durante los meses de abril, mayo y junio de 2020, la leve recuperación durante el verano de ese mismo año, la subsiguiente disminución de la demanda, en buena medida por motivos estacionales, y, finalmente, una 
evidente expansión a partir de mayo de 2021. De hecho, el número de evaluaciones registradas en agosto de 2021 duplica las del año anterior, y la de septiembre de 2021 está muy próxima a la del mismo mes de 2019, antes de la pandemia. Estos datos apuntan a que la resiliencia del turismo urbano en la ciudad de Málaga no se limitó al mercado convencional (hoteles) sino que se manifiesta también en el mercado p2p. Sobre esa base, es previsible que se planteen de nuevo los debates que estaban abiertos antes de la pandemia sobre los efectos que provoca la expansión del mercado p2p en las ciudades.

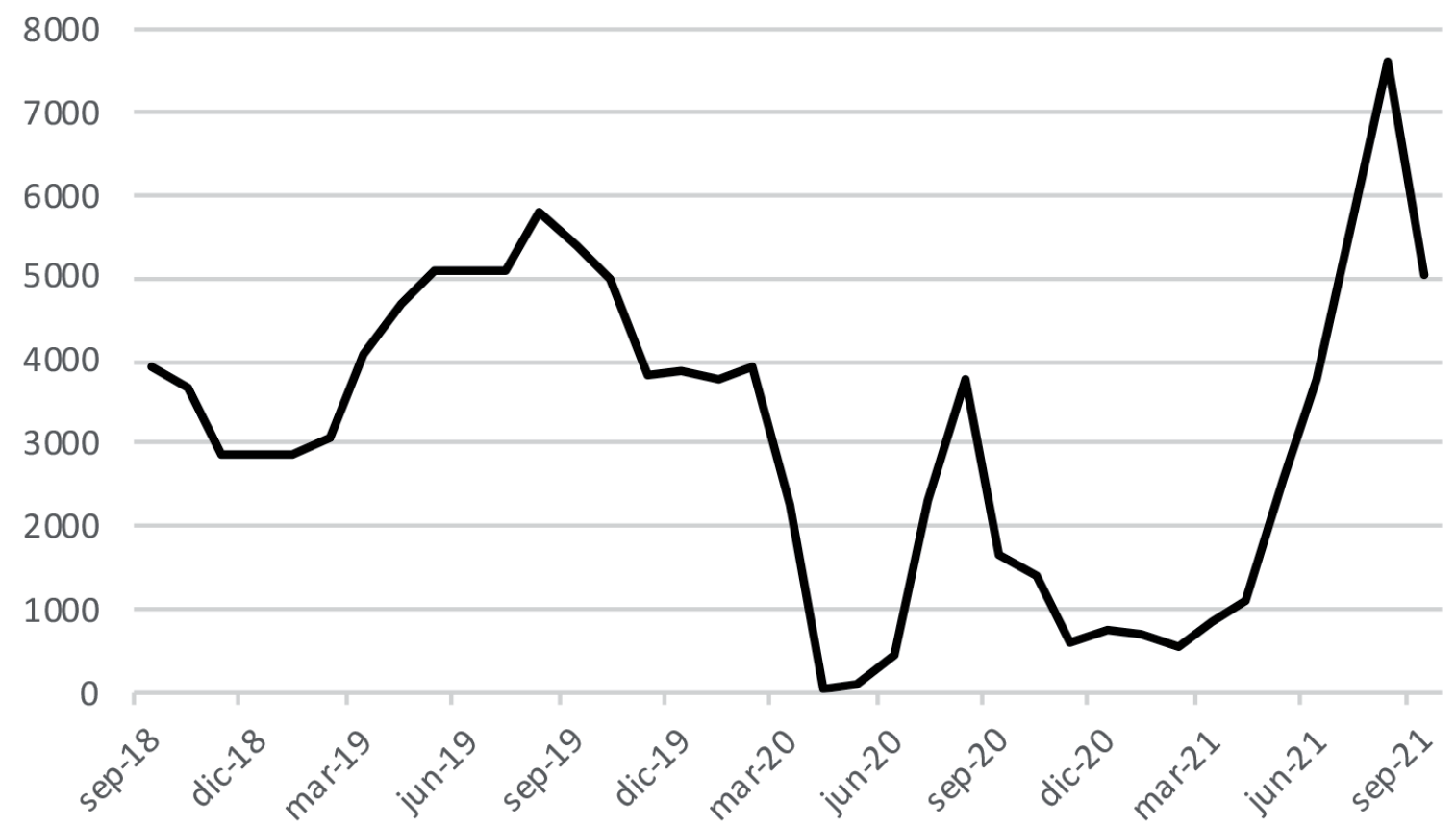

Figura 4. Evolución del número de evaluaciones de los anuncios activos el 30 de septiembre de 2021. Fuente: Elaboración propia a partir de InsideAirbnb (2021).

Por el lado de la oferta la información disponible nos permite un ejercicio de estática comparativa con los datos de scrapings realizados a los anuncios de Airbnb en la ciudad de Málaga el 1 de septiembre de 2019 y el 30 de septiembre de 2021. Así, a partir de los datos de la tabla 2, se observa que la oferta de alojamientos disminuyó. Los anuncios lo hicieron en 363 (un 6\%) y el número de huéspedes que potencialmente pueden ser alojados en 2.557 (un 10\%). Es posible que, dadas las reducidas barreras de entrada y salida que posee la oferta en este mercado, durante la pandemia se haya producido una reducción de la oferta que aún no se haya recuperado. En principio, esta flexibilidad es mayor que la que tienen los alojamientos convencionales lo que, en última instancia, le permite ciertas ventajas competitivas (Einav et al., 2016).

Ahora bien, el hecho de que la oferta de alojamientos en el mercado p2p sea menor no equivale necesariamente a una reducción efectiva del mercado. Los datos de los que hemos podido disponer no permiten distinguir qué alojamientos han salido del mercado o si se ha producido un trasvase de la oferta de viviendas desde el alquiler a corto plazo hacia el alquiler a largo plazo como, a nivel general, han sugerido Dolnicar y Zare (2020). No obstante, de acuerdo con la lógica económica, cabe plantear la hipótesis de que la reducción de la oferta se haya producido, precisamente, en los alojamientos menos rentables, es decir, los menos demandados. Aquí conviene recordar que existe evidencia de que un elevado porcentaje de alojamientos en el mercado p2p apenas son demandados (Benítez-Aurioles, 2020a). Sobre esa base, es posible que, ante la recuperación de la demanda, se haya producido una utilización más intensa de los alojamientos disponibles con lo que, en última instancia, la presión turística que ejerce el mercado p2p pueda estar recuperando los niveles que tenía antes de la pandemia. Esta conjetura viene avalada por el hecho de que el número medio de evaluaciones entre los anuncios que estaban activos el 30 de septiembre de 2019 y habían recibido, al 
menos, una evaluación, era 35, mientras que, entre los anuncios activos el 30 de septiembre de 2021, había subido a 42. Es decir, habría menos alojamientos, pero con un grado de ocupación mayor.

Tabla 2. Indicadores de oferta en el mercado peer-to-peer.

\begin{tabular}{|l|c|c|c|}
\hline & 1-Sep-19 [1] & 30-Sep-21 [2] & [2]-[1] \\
\hline Número de anuncios & 6.019 & 5.656 & -363 \\
\hline Número de huéspedes potenciales & 25.543 & 22.986 & -2.557 \\
\hline \% alojamientos completos & 84,4 & 85,8 & 1,4 \\
\hline Número de anfitriones & 2.610 & 2.297 & -313 \\
\hline \% anuncios ofrecidos por profesionales & 70,2 & 72,7 & 2,5 \\
\hline \% de Superhosts & 22,2 & 24,3 & 2,1 \\
\hline \% de reserva instantánea & 76,6 & 66,5 & $-10,1$ \\
\hline
\end{tabular}

Fuente: Elaboración propia a partir de InsideAirbnb (2021).

En cuanto al tipo de alojamientos ofrecidos se consolida la oferta de viviendas completas que crecen levemente hasta alcanzar el $85,8 \%$ del total de la oferta, lo cual confirma la idea de que Airbnb, más que una plataforma que permite compartir el espacio sobrante en una vivienda, está dedicada a la comercialización del alquiler de viviendas completas a corto plazo (Gyódi, 2019).

El número de anfitriones se redujo durante el periodo considerado en un $12 \%$ y, al mismo tiempo, creció el porcentaje de anuncios ofrecidos por anfitriones que posee más de un alojamiento, y el de los que tenían la etiqueta Superhosts, lo cual es compatible con una mayor profesionalización del mercado. En muchos casos, la oferta es realizada por empresas que gestionan de forma integral el alquiler de los apartamentos en nombre de los verdaderos propietarios. Por ejemplo, Luckey es una empresa que fue adquirida por la propia Airbnb en diciembre de 2018 y que por una comisión del $20 \%$ se encargan de todo el proceso, desde la gestión de la entrada y salida de los huéspedes hasta la limpieza y el mantenimiento de los alojamientos (Luckey, 2021).

También es destacable la reducción en algo más de 10 puntos del porcentaje de reservas que pueden realizarse de forma instantánea, lo cual podría ser indicativo del mayor interés de los anfitriones por seleccionar el tipo de turista que recibe. Este dato merece una reflexión adicional ya que, desde Airbnb (2021c) se ha promocionado la opción de reserva instantánea, igual que existe en los alojamientos convencionales, ante la evidencia de que la posibilidad de que sea necesaria la confirmación del anfitrión para validar la reserva pueda estar facilitando la discriminación de algunas minorías étnicas (Edelman et al., 2017) o de personas con una determinada orientación sexual (Ahuja \& Lyons, 2017). No obstante, con la información disponible no es posible determinar las razones por las que ha disminuido el porcentaje de anuncios de Airbnb que, en la ciudad de Málaga, permiten una reserva instantánea, aunque cabe la posibilidad de que esté relacionado con la búsqueda por parte de los anfitriones de una mayor seguridad sanitaria tras la pandemia.

Por último, para el análisis de la formación de los precios en el mercado p2p de alojamientos turísticos, los datos disponibles nos han permitido estimar la ecuación [1] antes (1 de septiembre de 2019) y después de la pandemia (30 de septiembre de 2021). En ambos casos, el poder explicativo del modelo es similar $(R 2=0,51)$. Asimismo, los parámetros que acompañan a algunas variables no solo mantienen los signos esperados, sino que su valor es, prácticamente, el mismo. Así ocurre con el número máximo de huéspedes que potencialmente pueden ser alojados (AC), con la vivienda completa (EH), y con el número de evaluaciones por anuncio (NR). La constante también mantiene el mismo valor. La distancia (DI), en cambio, parece perder relevancia: mientras que antes de la pandemia tiene el signo esperado con elevada significación estadística, después pierde la significación estadística y su influencia en la determinación de los precios de los alojamientos. No obstante, quizás los cambios más reseñables se hayan producido en los parámetros de las 
variables relacionadas con los anfitriones y su política de reserva. En este sentido, pierde influencia la etiqueta Superhost (SH) mientras que lo gana el número de anuncios por anfitrión (Ln L). Asimismo, es destacable el cambio de signo del parámetro relacionado con la reserva instantánea (IB) que pasa a ser positivo al final del periodo. Probablemente, estos cambios estén relacionados con la mayor importancia que han adquirido los oferentes profesionales en el mercado $\mathrm{p} 2 \mathrm{p}$.

Tabla 3. Resultados de la regresión de la ecuación [1].

\begin{tabular}{|c|c|c|}
\hline & 1-Sep-19 & 30-Sep-21 \\
\hline AC. Número máximo de huéspedes & $0,12 * \star *$ & $0,12 * * *$ \\
\hline EH. Vivienda completa & $0,61 * * *$ & $0,61 * * *$ \\
\hline DI. Distancia en kilómetros a plaza Constitución & $-0,013 * * *$ & 0,003 \\
\hline SH. Superhost & $0,06 * * *$ & $0,03 * *$ \\
\hline Ln L. Logaritmo del número de anuncios por anfitrión & $0,015 * * *$ & $0,043 * * *$ \\
\hline IB. Reserva instantánea & $-0,03 *$ & $0,07 * * *$ \\
\hline NR. Número de evaluaciones por anuncio & $-0,001 * * *$ & $-0,001 * * *$ \\
\hline Constante & $3,16 * \star \star$ & $3,16 * * *$ \\
\hline N. Número de observaciones & 3.589 & 3.263 \\
\hline R2-ajustado & 0,51 & 0,51 \\
\hline
\end{tabular}

\section{CONCLUSIONES}

La pandemia de la COVID-19 ha provocado una crisis sin precedentes que ha afectado, con especial intensidad, al turismo. No obstante, el progresivo avance de la vacunación y la eliminación de las restricciones a la movilidad permitieron que la actividad turística empezara a dar señales de recuperación. En este contexto, el análisis de la resiliencia del turismo urbano, que ha recibido una creciente atención desde el punto de vista académico, tiene una especial relevancia dado el debate abierto, antes de la pandemia, sobre la presión que estaba ejerciendo el turismo en determinadas ciudades. El caso de Málaga es una buena referencia, no sólo por la importancia absoluta y relativa que posee la actividad turística en la generación de renta y de empleo, sino por el peso que tiene el mercado p2p de alojamientos turísticos que ha sido, frecuentemente, señalado como el catalizador de impactos negativos asociados al overtourism.

Entre los diversos enfoques metodológicos que pueden adoptarse para el estudio del turismo urbano, el marco teórico que proporciona el análisis económico resulta pertinente para conocer los vectores básicos que condicionan el funcionamiento del mercado turístico, es decir, la demanda, la oferta y los precios. Asimismo, dadas las diferencias que existen entre el mercado de alojamientos convencionales y el mercado p2p de alquiler de viviendas a corto plazo, es conveniente un análisis separado.

Tomando como base la Encuesta de Ocupación Hotelera del INE, el análisis del mercado de alojamientos convencionales ha mostrado evidentes signos de recuperación a partir de los meses de abril y mayo de 2021. En este sentido, es destacable la resiliencia demostrada por el turismo urbano, al menos en la ciudad de Málaga, y el protagonismo adquirido por el turismo nacional. En efecto, todo apunta a que los residentes en España sustituyeron los viajes internacionales por los nacionales con lo que, a diferencia de lo que ocurría antes de la pandemia, ha superado al turismo realizado por los extranjeros, tanto en términos de viajeros como de pernoctaciones hoteleras. Adicionalmente, aumentó, hasta alcanzar cifras históricas, la 
estancia media en los hoteles de la ciudad lo que podría conectarse con el cambio del comportamiento que ha propiciado el turista nacional.

Otros indicadores, como el número de habitaciones estimadas, su grado de ocupación o el personal empleado por los hoteles, confirman la resiliencia del sector desde la primavera de 2021. El hecho de que se haya producido, a partir de entonces, una subida del ADR y del RevPAR hace pensar que la intensidad en la recuperación de la demanda, ha compensado el incremento de la oferta, y, en consecuencia, es lo que explica la subida de los precios en el mercado de alojamientos convencionales.

Por su parte, el mercado $\mathrm{p} 2 \mathrm{p}$ de alojamientos turísticos también demuestra unos patrones de resiliencia similares al del mercado convencional y, más concretamente, una fuerte recuperación de la demanda partir de mayo de 2021. Asimismo, un análisis más concreto de la oferta confirma la preponderancia de la comercialización de viviendas completas y el de los anfitriones que ofrecen más de un alojamiento. Es decir, parece fortalecerse la tendencia hacia un mercado en el que la oferta está en manos de profesionales que, básicamente, se dedican al alquiler de viviendas completas a corto plazo, lo que, en última instancia, podría explicar ciertos cambios en el proceso de formación de precios tras la pandemia.

De acuerdo con lo anterior, se constata la resiliencia del turismo urbano, al menos en la ciudad de Málaga, tanto en el mercado convencional (hoteles) como en el mercado p2p (Airbnb). Además, las características de esta recuperación tienen algunas implicaciones prácticas tanto para el ámbito privado como público. Así, el protagonismo que ha tenido el turismo nacional en la demanda turística de alojamientos en los hoteles y la prolongación de la estancia puede servir de base para la articulación, por parte de los gestores privados, de campañas de promoción especialmente orientadas a los turistas residentes en España. Por otro lado, el resurgimiento del mercado $\mathrm{p} 2 \mathrm{p}$ de alojamientos turísticos reabre el debate sobre la capacidad de carga de las ciudades y la pertinencia de su regulación.

\section{Agradecimientos}

La autora agradece los comentarios y sugerencias de dos evaluadores anónimos, así como la labor del equipo editorial de la Revista de Estudios Andaluces. En cualquier caso, los errores y carencias que pudiera tener este artículo son de exclusiva responsabilidad de la autora.

\section{Declaración responsable y conflicto de intereses}

La autora garantiza la autoría y originalidad del artículo, y asume la plena y exclusiva responsabilidad por los daños y perjuicios que pudieran producirse como consecuencia de reclamaciones de terceros respecto del contenido, autoría o titularidad del contenido del mismo. Asimismo, la autora declara que no existe ningún conflicto de interés con relación a la publicación de este artículo.

\section{REFERENCIAS}

Ahuja, R. \& Lyons, R. (2017). The Silent Treatment: LGBT Discrimination in the Sharing Economy, Trinity Economics Papers tep1917. Trinity College Dublin, Department of Economics. https://www.tcd.ie/Economics/TEP/2017/tep1917.pdf

Airbnb (2021a). Evaluaciones de alojamientos. https://www.airbnb.es/help/article/13/evaluaciones-de-alojamientos?_set_ bev_on_new_domain=1602779486_mIqcHLyDNsehfobD

Airbnb (2021b). Superhost: un premio a los mejores anfitriones. https://www.airbnb.es/d/superhost

Airbnb (2021c). Cómo utilizar la Reserva inmediata. https://www.airbnb.es/help/article/1510/c\%C3\%B3mo-utilizar-la-reserva-inmediata

AirDNA (2021). Vacation Rental Data to Set You Apart. Insights to Keep You Ahead. https://www.airdna.co/ 
Alsudais, A. (2021). Incorrect data in the widely used Inside Airbnb dataset. Decision Support Systems, 141, 113453. https:// doi.org/10.1016/j.dss.2020.113453

Arbulú, I., Razumova, M., Rey-Maquieira, J. \& Sastre, F. (2021). Can domestic tourism relieve the COVID-19 tourist industry crisis? The case of Spain. Journal of Destination Marketing \& Management, 20, 100568. https://doi.org/10.1016/j. jdmm.2021.100568

Ashworth, G. J. (1992). Is there an urban tourism? Tourism Recreation Research, 17(2), 3-8. https://doi.org/10.1080/02508 281.1992.11014645

Ashworth, G. \& Page, S. J. (2011). Urban tourism research: Recent progress and current paradoxes. Tourism Management, 32(1), 1-15. https://doi.org/10.1016/j.tourman.2010.02.002

Ayuntamiento de Málaga (2021). Plan estratégico turismo de Málaga 2021-2024. http://s3.malagaturismo.com/files/933/933/plan-estrategico-turismo-2021-2024-def.pdf

Belk, R. (2014). Sharing versus pseudo-sharing in Web 2.0. The Anthropologist, 18(1), 7-23. https://doi.org/10.1080/0972 0073.2014 .11891518

Benítez-Aurioles, B. (2018a). Estrategias de comunicación: Airbnb versus hoteles/Communication strategies: Airbnb versus hotels. Revista Internacional de Relaciones Públicas, 8(16), 47-66. http://dx.doi.org/10.5783/RIRP-16-2018-04-4766

Benítez-Aurioles, B. (2018b). Why are flexible booking policies priced negatively? Tourism Management, 67, 312-325. https://doi.org/10.1016/j.tourman.2018.02.008

Benítez-Aurioles, B. (2018c). The role of distance in the peer-to-peer market for tourist accommodation. Tourism Economics, 24(3), 237-250. https://doi.org/10.1177/1354816617726211

Benítez-Aurioles, B. (2019a). Barcelona's peer-to-peer tourist accommodation market in turbulent times: terrorism and political uncertainty. International Journal of Contemporary Hospitality Management, 31(12), 4419-4437. https://doi. org/10.1108/IJCHM-01-2019-0090

Benítez-Aurioles, B. (2019b). Is Airbnb bad for hotels? Current Issues in Tourism, 1-4. https://doi.org/10.1080/13683500.2 019.1646226

Benítez-Aurioles, B. (2020a). Tourism Resilience Patterns in Southern Europe. Tourism Analysis, 25(4), 409-424. https://doi. org/10.3727/108354220X16010020096118

Benítez-Aurioles, B. (2020b). The exhaustion of the herding effect in peer-to-peer accommodation. Tourism Economics, 1354816620946537. https://doi.org/10.1177/1354816620946537

Benítez-Aurioles, B. (2021a). Uncertainty and tourism. A regional approach. Investigaciones Turísticas, 22, 52-68. https:// doi.org/10.14198/INTURI2021.22.3

Benítez-Aurioles, B. (2021b). El turismo interior en España ante la crisis de la COVID-19. Boletín económico de ICE, Información Comercial Española, 3139, 43-53. https://doi.org/10.32796/bice.2021.3139.7285

Benítez-Aurioles, B. \& Tussyadiah, I. P. (2020). What Airbnb does to the housing market. Annals of Tourism Research, 103108. https://doi.org/10.1016/j.annals.2020.103108

Blake, A. \& Sinclair, M. T. (2003). Tourism crisis management: US response to September 11. Annals of Tourism Research, 30(4), 813-832. https://doi.org/10.1016/S0160-7383(03)00056-2

Camilleri, J. \& Neuhofer, B. (2017). Value co-creation and co-destruction in the Airbnb sharing economy. International Journal of Contemporary Hospitality Management, 29(9), 2322-2340. https://doi.org/10.1108/IJCHM-09-2016-0492

Comendador-Sánchez, A., Santos-Pavón, E. \& Hernández-Ramírez, J. (2021). Players, interests and public policies in relation to tourist rental housing in Spain (2010-2019). Complexity and multiple conflicts. Journal of Tourism Analysis: Revista de Análisis Turístico (JTA), 28(1), 1-21. https://doi.org/10.53596/jta.v28i1.373

Cooper, M. (2006). Japanese tourism and the SARS epidemic of 2003. Journal of Travel \& Tourism Marketing, 19(2-3), 117131. https://doi.org/10.1300/J073v19n02_10

Corbet, S., O'Connell, J. F., Efthymiou, M., Guiomard, C. \& Lucey, B. (2019). The impact of terrorism on European tourism. Annals of Tourism Research, 75, 1-17. https://doi.org/10.1016/j.annals.2018.12.012

Dann, D., Teubner, T. \& Weinhardt, C. (2019). Poster child and guinea pig-insights from a structured literature review on Airbnb. International Journal of Contemporary Hospitality Management, 31(1), 427-473. https://doi.org/10.1108/ IJCHM-03-2018-0186 
Deale, C. S., \& Crawford, A. (2018). Providers' perceptions of the online community marketplace for lodging accommodations. Tourism and Hospitality Research, 18(4), 470-477. https://doi.org/10.1177/1467358416682067

Deane, S. (2021). 2021 Airbnb Statistics: Usage, Demographics, and Revenue Growth. https://www.stratosjets.com/blog/ airbnb-statistics/

Dolnicar, S. (2019). A review of research into paid online peer-to-peer accommodation: Launching the Annals of Tourism Research curated collection on peer-to-peer accommodation. Annals of Tourism Research, 75, 248-264. https://doi. org/10.1016/j.annals.2019.02.003

Dolnicar, S. \& Zare, S. (2020). COVID19 and Airbnb-Disrupting the disruptor. Annals of Tourism Research, 83, 102961. https://doi.org/10.1016/j.annals.2020.102961

Edelman, B., Luca, M., \& Svirsky, D. (2017). Racial discrimination in the sharing economy: Evidence from a field experiment. American Economic Journal: Applied Economics, 9(2), 1-22. https://doi.org/10.1257/app.20160213

Edwards, D., Griffin, T. \& Hayllar, B. (2008). Urban tourism research: developing an agenda. Annals of Tourism Research, 35(4), 1032-1052. https://doi.org/10.1016/j.annals.2008.09.002

Einav, L., Farronato, C. \& Levin, J. (2016). Peer-to-peer markets. Annual Review of Economics, 8, 615-635. https://doi. org/10.1146/annurev-economics-080315-015334

Exceltur (2017). Monitor de competitividad turística de los destinos urbanos españoles. Urbantur 2016. https://www.exceltur. org/

Exceltur (2021). Barómetro de la rentabilidad de los destinos turísticos españoles. https://www.exceltur.org/wp-content/ uploads/2021/02/Baro\%CC\%81 metro-Rentabilidad-y-el-Empleo-Enero-Diciembre-2020.pdf

Gassmann, S.-E., Nunkoo, R., Tiberius, V. \& Kraus, S. (2021). My home is your castle: forecasting the future of accommodation sharing. International Journal of Contemporary Hospitality Management, 33(2), 467-489. https://doi.org/10.1108/ IJCHM-06-2020-0596

Gibbs, C., Guttentag, D., Gretzel, U., Morton, J. \& Goodwill, A. (2018a). Pricing in the sharing economy: A hedonic pricing model applied to Airbnb listings. Journal of Travel \& Tourism Marketing, 35(1), 46-56. https://doi.org/10.1080/10548 408.2017.1308292

Gurran, N. \& Phibbs, P. (2017). When tourists move in: how should urban planners respond to Airbnb? Journal of the American Planning Association, 83(1), 80-92. https://doi.org/10.1080/01944363.2016.1249011

Guttentag, D. (2015). Airbnb: disruptive innovation and the rise of an informal tourism accommodation sector. Current issues in Tourism, 18(12), 1192-1217. https://doi.org/10.1080/13683500.2013.827159

Guttentag, D. (2019). Progress on Airbnb: a literature review. Journal of Hospitality and Tourism Technology. https://doi. org/10.1108/JHTT-08-2018-0075

Gyódi, K. (2019). Airbnb in European cities: Business as usual or true sharing economy?. Journal of Cleaner Production, 221, 536-551. https://doi.org/10.1016/j.jclepro.2019.02.221

Hajibaba, H. \& Dolnicar, S. (2018). Airbnb and its Competitors. En S. Dolnicar (Ed.) Peer-to-Peer Accommodation Networks: Pushing the boundaries (pp. 63-76). Oxford: Goodfellow Publishers. https://dx.doi.org/10.23912/97819113965123604

Hartmans, A. (2017). Airbnb now has more listings worldwide than the top five hotel brands combined, BusinessInsider. https://www.businessinsider.com/airbnb-total-worldwide-listings-2017-8

Hati, S. R. H., Balqiah, T. E., Hananto, A. \& Yuliati, E. (2021). A decade of systematic literature review on Airbnb: the sharing economy from a multiple stakeholder perspective. Heliyon, 7(10), e08222. https://doi.org/10.1016/j.heliyon.2021. e08222

Hocevar, M. \& Bartol, T. (2021). Mapping urban tourism issues: analysis of research perspectives through the lens of network visualization. International Journal of Tourism Cities. 7(3), 818-844. https://doi.org/10.1108/IJTC-05-2020-0110

Hu, M. R. \& Lee, A. D. (2020). Airbnb, COVID-19 Risk and Lockdowns: Global Evidence. https://papers.ssrn.com/sol3/ papers.cfm?abstract_id=3589141

Ikeji, T. \& Nagai, H. (2020). Residents' attitudes towards peer-to-peer accommodations in Japan: Exploring hidden influences from intergroup biases. Tourism Planning \& Development, 18(5), 491-509. https://doi.org/10.1080/2156831 6.2020 .1807400

Ikkala T. \& Lampinen A. (2014) Defining the Price of Hospitality: Networked Hospitality Exchange via Airbnb. CSCW, Baltimore, 173-176. https://doi.org/10.1145/2556420.2556506 
INE (2019). Encuesta de Ocupación Hotelera. Metodología. https://ine.es/daco/daco42/ocuphotel/meto_eoh.pdf

INE (2021a). Estimación de la ocupación en alojamientos turísticos a partir de datos de plataformas digitales. https://ine.es/ experimental/ocupacion/experimental_ocupacion.htm

INE (2021b). Indicadores Urban Audit para Ciudades. https://www.ine.es/jaxiT3/Tabla.htm?t=30140

INE (2021c). Encuesta de Ocupación Hotelera. https://ine.es/dyngs/INEbase/es/operacion.htm?c=Estadistica_C\&ci$\mathrm{d}=1254736177015 \&$ menu=ultiDatos\&idp=1254735576863

InsideAirbnb (2021). Get the Data. http://insideairbnb.com/get-the-data.html

Jiménez, J. L., Ortuño, A. \& Pérez-Rodríguez, J. V. (2021). How does AirBnb affect local Spanish tourism markets?. Empirical Economics, 1-31. https://doi.org/10.1007/s00181-021-02107-2

Karlsson, L. \& Dolnicar, S. (2016). Someone's been sleeping in my bed. Annals of Tourism Research, 58, 159-162. https:// doi.org/10.1016/j.annals.2016.02.006

Li, J., Moreno, A. \& Zhang, D. J. (2019). Agent Pricing in the Sharing Economy: Evidence from Airbnb. In M. Hu (Ed.) Sharing Economy (pp. 485-503). Cham: Springer. https://doi.org/10.1007/978-3-030-01863-4_20

Liang, S., Schuckert, M., Law, R. \& Chen, C-C. (2017). Be a 'Superhost': The importance of badge systems for peer-to-peer rental accommodations. Tourism Management, 60, 454-465. https://doi.org/10.1016/j.tourman.2017.01.007

Luckey (2021). Gestión de apartamentos turísticos en Airbnb. https://luckey.es/

Magno, F., Cassia, F.\& Ug olini, M. M. (2018). Accommodation prices on Airbnb: effects of host experience and market demand. The TQM Journal, 30(5), 608-620. https://doi.org/10.1108/TQM-12-2017-0164

Martín, E. G. \& Gimeno, M. V. (2021). Encuestas de Ocupación en Alojamientos Turísticos. Índices de Precios e Indicadores de Rentabilidad del Sector Hotelero. Indice: Revista de Estadística y Sociedad, (80), 26-32. http://www.revistaindice.com/numero80/p26.pdf

McKercher, B. \& Chon, K. (2004). The over-reaction to SARS and the collapse of Asian tourism. Annals of Tourism Research, 31(3), 716-719. https://doi.org/10.1016/j.annals.2003.11.002

Möhlmann, M. (2015). Collaborative consumption: determinants of satisfaction and the likelihood of using a sharing economy option again. Journal of Consumer Behaviour, 14(3), 193-207. https://doi.org/10.1002/cb.1512

Namberger, P., Jackisch, S., Schmude, J. \& Karl, M. (2019). Overcrowding, overtourism and local level disturbance: how much can Munich handle?. Tourism Planning \& Development, 16(4), 452-472. https://doi.org/10.1080/21568316.201 9.1595706

Observatorio turístico de la ciudad de Málaga (s.f.). Enero 2019 - Diciembre 2019. http://s3.malagaturismo.com/files/974/974/presentacion-observatorio-turistico-ciudad-de-malagaene19dic19100320-2.pdf

Oskam, J. \& Boswijk, A. (2016). Airbnb: the future of networked hospitality businesses. Journal of Tourism Futures, 2(1), 22-42. https://doi.org/10.1108/JTF-11-2015-0048

Oskam, J. A. (2020). Commodification of the 'Local' in Urban Tourism: The Airbnb Contradiction. En J. A. Oskam (Ed.) The Overtourism Debate, Emerald Publishing Limited, Bingley (pp. 151-170). https://doi.org/10.1108/978-1-83867-487820201011

Ozdemir, G. \& Turker, D. (2019). Institutionalization of the sharing in the context of Airbnb: a systematic literature review and content analysis. Anatolia, 30(4), 601-613. https://doi.org/10.1080/13032917.2019.1669686

Pechlaner, H. \& Frehse, J. (2010). Financial crisis and tourism. En R. Conrady \& M. Buck (Eds.) Trends and Issues in Global Tourism 2010 (pp. 27-38). Berlin, Heidelberg: Springer. https://doi.org/10.1007/978-3-642-10829-7_4

Prayag, G. \& Ozanne, L. K. (2018). A systematic review of peer-to-peer (P2P) accommodation sharing research from 2010 to 2016: progress and prospects from the multi-level perspective. Journal of Hospitality Marketing \& Management, 27(6), 649-678. https://doi.org/10.1080/19368623.2018.1429977

Priporas, C. V., Stylos, N., Rahimi, R. \& Vedanthachari, L. N. (2017). Unraveling the diverse nature of service quality in a sharing economy: A social exchange theory perspective of Airbnb accommodation. International Journal of Contemporary Hospitality Management, 29(9), 2279-2301. https://doi.org/10.1108/IJCHM-08-2016-0420

Reinhold, S. \& Dolnicar, S. (2018). The Sharing Economy. In S. Dolnicar (Ed.) Peer-to-Peer Accommodation Networks: Pushing the boundaries (pp. 15-26). Oxford: Goodfellow Publishers. http://dx.doi.org/10.23912/9781911396512-3600

Rosselló, J., Becken, S. \& Santana-Gallego, M. (2020). The effects of natural disasters on international tourism: A global analysis. Tourism Management, 79, 104080. https://doi.org/10.1016/j.tourman.2020.104080 
Sainaghi, R. (2020). The current state of academic research into peer-to-peer accommodation platforms. International Journal of Hospitality Management, 89. https://doi.org/10.1016/j.ijhm.2020.102555

Schor, J. (2016). Debating the sharing economy. Journal of Self-Governance and Management Economics, 4(3), 7-22. https:// doi.org/10.22381/jsme4320161

Smith, M. K., Sziva, I. P. \& Olt, G. (2019). Overtourism and resident resistance in Budapest. Tourism Planning \& Development, 16(4), 376-392. https://doi.org/10.1080/21568316.2019.1595705

Tussyadiah, I. P. (2016). Factors of satisfaction and intention to use peer-to-peer accommodation. International Journal of Hospitality Management, 55, 70-80. https://doi.org/10.1016/j.ijhm.2016.03.005

Tussyadiah, I. P. \& Pesonen, J. (2016). Impacts of peer-to-peer accommodation use on travel patterns. Journal of Travel Research, 55(8), 1022-1040. https://doi.org/10.1177/0047287515608505

Tussyadiah, I. P. \& Zach, F. (2017). Identifying salient attributes of peer-to-peer accommodation experience. Journal of Travel \& Tourism Marketing, 34(5), 636-652. https://doi.org/10.1080/10548408.2016.1209153

UNWTO (2018). 'Overtourism'? Understanding and managing urban tourism growth beyond perceptions. Madrid: UNWTO. https://doi.org/10.18111/9789284420070

UNWTO (2019), Definiciones de turismo de la OMT, OMT, Madrid, https://doi.org/10.18111/9789284420858

UNWTO (2021). 2020: Worst year in tourism history with 1 billion fewer international arrivals. https://www.unwto.org/ news/2020-worst-year-in-tourism-history-with-1-billion-fewer-international-arrivals

Wang, D. \& Nicolau, J. L. (2017). Price determinants of sharing economy based accommodation rental: A study of listings from 33 cities on Airbnb.com. International Journal of Hospitality Management, 62, 120-131. https://doi.org/10.1016/j. ijhm.2016.12.007

Wiles, A. \& Crawford, A. (2017). Network hospitality in the share economy: Understanding guest experiences and the impact of sharing on lodging. International Journal of Contemporary Hospitality Management, 29(9), 2444-2463. https:// doi.org/10.1108/IJCHM-08-2016-0453

Wu, J., Zeng, M. \& Xie, K. L. (2017). Chinese travelers' behavioral intentions toward room-sharing platforms: The influence of motivations, perceived trust, and past experience. International Journal of Contemporary Hospitality Management, 29(10), 2688-2707. https://doi.org/10.1108/IJCHM-08-2016-0481

Zheng, W., Ji, H., Lin, C., Wang, W. \& Yu, B. (2020). Using a heuristic approach to design personalized urban tourism itineraries with hotel selection. Tourism Management, 76, 103956. https://doi.org/10.1016/j.tourman.2019.103956 